Research Paper

\title{
TGF $\beta 1$ induces bone formation from BMP9-activated Bone Mesenchymal Stem Cells, with possible involvement of non-canonical pathways
}

\author{
Huan $\mathrm{Yao}^{1^{*}}$, Yulong Zou ${ }^{2 *}$, Ke Yang 3 , Liangjun Yin², Yang Liu² and Ruidong Li2 ${ }^{\circledR}$ \\ 1. The First Affiliated Hospital, Chongqing Medical University, Chongqing, China. \\ 2. Department of Orthopaedic Surgery, the Second Affiliated Hospital, Chongqing Medical University, Chongqing, China. \\ 3. The Children's Hospital, Chongqing Medical University, Chongqing, China. \\ *These authors contributed equally to this work. \\ $\bowtie$ Corresponding author: Ruidong Li, Tel.: +86-23-6369-3558; E-mail: stablee@cqmu.edu.cn.
}

(c) The author(s). This is an open access article distributed under the terms of the Creative Commons Attribution License (https://creativecommons.org/licenses/by/4.0/). See http://ivyspring.com/terms for full terms and conditions.

Received: 2020.03.08; Accepted: 2020.06.12; Published: 2020.07.02

\begin{abstract}
Reconstruction of bone defects is one of the most substantial and difficult clinical challenges in orthopedics. Transforming growth factor beta 1 (TGF $\beta 1$ ) might play an important role in stimulating osteogenic differentiation of bone morphogenetic protein 9 (BMP9)-induced C3H10T1/2 mesenchymal stem cells. In our current study, we examined the potential synergy between TGF $\beta 1$ and BMP9 in promoting the osteogenesis of $\mathrm{C} 3 \mathrm{H} 10 \mathrm{~T} 1 / 2$ cells, and whether such effects could contribute to bone formation in vivo. Our experiment data indicated that TGF $\beta 1$ could increase the expression of osteogenic markers and the formation of mineralized calcium nodules in, while suppressing the proliferation of, BMP9-induced C3H10T1/2 cells. Furthermore, mice intramuscularly injected with BMP9/TGF $\beta 1$-transduced $\mathrm{C} 3 \mathrm{H} 10 \mathrm{T1} / 2$ cells into the gastrocnemius muscle on their tibiae developed ectopic bone masses with more mature osteoid structures, compared to those grafted with cells expressing BMP9/RFP. Subsequent mechanistic studies found that TGF $\beta 1$-induced enhancement of osteogenesis in BMP9-overexpressing $\mathrm{C} 3 \mathrm{H} 10 \mathrm{~T} 1 / 2$ cells was accompanied by augmented expression of heat shock protein 47 (HSP47), a collagen-specific molecular chaperone essential for collagen biosynthesis, and can be attenuated by pirfenidone, a known anti-fibrotic inhibitor. Interestingly, protein microarray analysis suggested that TGF 31 /BMP9-dependent osteogenesis of C3H10T1/2 cells seemed to involve several non-canonical signaling pathways such as Janus kinase-signal transducer and activator of transcription, phosphoinositide-3-kinase-protein kinase $B$, and mitogen-activated protein kinase. These results provided further evidence that TGF $\beta 1$ could promote bone formation from BMP9-induced $\mathrm{C} 3 \mathrm{H} 10 \mathrm{~T} 1 / 2$ cells and shed important light on the underlying molecular mechanisms.
\end{abstract}

Key words: Osteogenesis; TGF $\beta 1$; BMP9; HSP47; Bone mesenchymal stem cell

\section{Introduction}

Reconstruction of bone defects caused by trauma is one of the most substantial and difficult clinical challenges in orthopedics [1, 2]. Recently, bone tissue engineering, which uses autologous or allogeneic tissues for bone defect repair, has emerged as a promising alternative to grafting [3]. There is consensus that success in bone tissue engineering entails an optimal combination of stem cells, growth factors and scaffolds. Bone marrow-derived mesenchymal stem cells (BMSC) have been widely viewed as promising candidates for bone tissue engineering because of their excellent pluripotency, affinity to plastic surface, and the ease with which they can be harvested and cultured [4, 5]. Extensive research has lent support to the potential efficacy of BMSCs for restoring various bone defects in laboratory animals such as mice $[6,7]$ and rats $[8,9]$. The C3H10T1/2 cell line, which is isolated from $\mathrm{C} 3 \mathrm{H}$ 
mice and immortalized, is one of the most representative acknowledged BMSCs at present [10, 11]. Although clinical evaluation of BMSCs is still exploratory, Gan et al. has demonstrated that they can effectively promote posterior spinal fusion when combined with porous $\beta$-tricalcium phosphate [12].

Bone morphogenetic protein 9 (BMP9) is a relatively obscure member of the BMP family and has recently been found to be a key regulator of osteogenic stem cell differentiation [13, 14]. In fact, there is evidence that BMP9 could be one of the most osteogenic BMPs both in vitro and in vivo [15]. For example, several studies have indicated that upregulation of BMP9 could dramatically increase the activity of alkaline phosphatase (ALP) and promote the deposition of calcium in C3H10T1/2 cells [9-11] and $\mathrm{C} 2 \mathrm{C} 12$ cells [16]. Similar effects have also been observed in animal models [17]. Although the mechanisms responsible for the osteo-inductive activities of BMP9 have not been fully elucidated, recent investigations suggested that the signaling pathway involves receptor binding of BMPs [18, 19] followed by the phosphorylative activation of mothers against decapentaplegic homolog (Smad), which are well-established osteogenic modulators [20].

Transforming growth factor beta 1 (TGF $\beta 1$ ), a master regulator of cell survival, proliferation and differentiation, has also been shown to play an important role in stimulating the growth of bone [21]. Unlike BMP9, while TGF $\beta 1$ alone has been shown to induce the osteogenic differentiation of oriented osteogenic ancestral cells, there is, to the best of our knowledge, no evidence that it can also exert the same effects on BMSCs $[22,23]$. TGF $\beta 1$ and BMP9 signaling pathways share a striking resemblance in that both are initiated by ligand binding to a heterodimeric complex of transmembrane receptor serine-threonine kinases [19], prompting speculation of possible cross-talk between them. Using supernatant obtained from a culture of TGF $\beta 1$-overexpressing HCT116 cells, we have previously discovered that TGF $\beta 1$ could exert an osteo-stimulatory effect on BMP9transduced $\mathrm{C} 3 \mathrm{H} 10 \mathrm{~T} 1 / 2$ cells at low concentrations, but would inhibit osteogenesis at high concentrations [22]. These findings thus suggested that much remains to be learned about the interaction between the TGF $\beta 1$ and the BMP9 signaling pathways in BMSCs, particularly in an in vivo setting. In the current study, we demonstrated that the same osteo-inductive effect could be observed in BMP9-stimulated C3H10T1/2 cells upon adenoviral transduction of TGF $\beta 1$ gene. Engraftment of these C3H10T1/2 cells into the gastrocnemius muscle on the tibiae of mice could indeed lead to augmented bone formation and maturation. Heat shock protein 47 (HSP47) was found to be up-regulated and could play a key role in promoting the development of osteoid structures by activating its downstream target collagen type 1 (COL1). Interestingly, Western blotting and protein microarray results revealed the activation of several non-Smad signaling pathways, including Janus kinase (JAK)-signal transducer and activator of transcription (STAT), phosphoinositide-3kinase (PI3K)-protein kinase B (Akt), and mitogenactivated protein kinase (MAPK). Taken together, the results offered useful insights into the molecular mechanisms responsible for TGF $\beta 1$-dependent osteoinduction of BMSCs.

\section{Methods}

\section{Reagents and cell culture}

HEK293 and C3H10T1/2 cell lines (ATCC, Manassas, Virginia, USA) were maintained in complete Dulbecco's Modified Eagle's Medium (DMEM) and complete Basal Medium Eagle (BME) (Gibco, Thermo Fisher Scientific, Waltham, Massachusetts, USA), respectively, at $37^{\circ} \mathrm{C}$ under a humidified atmosphere containing $5 \% \mathrm{CO}_{2}$.

Pirfenidone was purchased from AbMole Bioscience, USA, and dissolved in DMSO. For inhibition of HSP47, the above stock solution was added to suspensions of C3H10T1/2 cells to a final concentration of $1000 \mu \mathrm{g} / \mathrm{mL}$ as previously described [24].

\section{Construction of recombinant adenoviruses}

Recombinant adenoviruses were generated using the AdEasy Adenoviral Vector System [25]. Briefly, the coding sequences of human TGF $\beta 1$ and mouse BMP9 were inserted into a red fluorescent protein (RFP)-labeled adenoviral shuttle vector and a green fluorescent protein (GFP)-labeled adenoviral shuttle vector, respectively. The resultant constructs were linearized and transfected into HEK293 cells by Lipofectamine 2000 (Thermo Fisher Scientific, Waltham, Massachusetts, USA) to produce adenoviruses expressing both TGF $\beta 1$ and RFP (AdTGF $\beta 1-$ RFP) or both BMP9 and GFP (AdBMP9-GFP). RFP(AdRFP) and GFP-only (AdGFP) control viruses were constructed by transfecting HEK293 cells with the corresponding insert-free vectors.

\section{Optimization of $\mathrm{C} 3 \mathrm{H} 10 \mathrm{~T} 1 / 2$ cell infection with AdTGF $\beta$ 1-RFP}

C3H10T1/2 cells were grown to the exponential stage, seeded to a $25 \mathrm{~cm}^{2}$ culture flask, and then infected with AdBMP9-GFP for $10 \mathrm{~h}$. The infection efficiency of AdBMP9-GFP was set to $20 \%$ as it has been previously found that excessive up-regulation of 
BMP9 could mask the osteogenic effects of TGF $\beta 1$ [14, 22]. Then, the cells were seeded to 24-well plates and infected with different titers of AdTGF $\beta 1-R F P$. Transduction efficiency of TGF $\beta 1$ was estimated by measuring the percentage of RFP-positive C3H10T1/2 cells under a fluorescence microscope. The cells were cultivated in serum-free $\mathrm{BME}$ at $37^{\circ} \mathrm{C}$ under $5 \% \mathrm{CO}_{2}$ for $14 \mathrm{~d}$. The concentration of TGF $\beta 1$ in the culture, which correlated to transduction efficiency, was measured by using a TGF $\beta 1$ ELISA Kit (Enzo Life Sciences, Farmingdale, New York, USA) at the indicated days. A standard curve was generated by serially diluting a starting TGF $\beta 1$ solution from $4000 \mathrm{ng} / \mathrm{mL}$ to $62.5 \mathrm{ng} / \mathrm{mL}$. The obtained standard formula was: concentration $(\mathrm{ng} / \mathrm{mL})=\left[409.91 * \mathrm{OD}^{2}+\right.$ 741.75 * OD + 2.0791] / 500 .

\section{Quantitation of ALP activity}

C3H10T1/2 cells were consecutively infected with AdBMP9-GFP and AdTGF $31-R F P$ (or AdRFP in the control group) in 24-wells plates as described above, with a 10-h interval in between. At the indicated days, the cells were harvested, stained using an Alkaline Phosphatase Kit (Sigma-Aldrich, St. Louis, Missouri, USA) following the manufacturer's instructions, and observed under a bright-field microscope [25].

\section{Alizarin red staining}

Infected C3H10T1/2 cells were treated as described above and grown at $37{ }^{\circ} \mathrm{C}$ for $17 \mathrm{~d}$ in serum-free BME supplemented with $10 \mathrm{mM}$ $\beta$-glycerophosphate and $50 \mu \mathrm{g} / \mathrm{mL}$ ascorbic acid. At the indicated days, the cells were harvested, fixed with $0.05 \%(\mathrm{v} / \mathrm{v})$ glutaraldehyde at room temperature for $10 \mathrm{~min}$, rinsed with distilled water, and incubated with $0.4 \%$ Alizarin Red S (Solarbio, Beijing, China) for $5 \mathrm{~min}$. After removing the excess dye by rigorous washing with distilled water, the stained cells were visualized under a bright-field microscope to analyze the formation of mineralized calcium nodules.

\section{Western blotting}

Briefly, cells were lysed in Laemmli buffer consisting of $60 \mathrm{mM}$ Tris- $\mathrm{HCl}$ buffered at 6.8, 2\% $(\mathrm{w} / \mathrm{v})$ sodium dodecyl sulfate (SDS), $10 \%(\mathrm{w} / \mathrm{v})$ glycerol and $0.01 \%(\mathrm{w} / \mathrm{v})$ bromophenol blue. The resultant lysate was centrifuged at $13000 \mathrm{rpm}$ for 10 min and the supernatant was boiled for 5 min before being loaded onto a $4-20 \%$ gradient SDS-PAGE gel. After electrophoresis at $100 \mathrm{~V}$ for $75 \mathrm{~min}$, the separated proteins were transferred to an ImmobilonP PVDF membrane (Merck Millipore, Burlington, Massachusetts, USA) at $4{ }^{\circ} \mathrm{C}$ and $30 \mathrm{~V}$ overnight, and submerged in a blocking buffer (SuperBlock, Thermo Fisher Scientific, Waltham, Massachusetts, USA) for 1 h. The membrane was stained by a primary antibody of choice that targets runt-related transcription factor 1 (Runx2), COL1, osteopontin (OPN), osteocalcin $(\mathrm{OCN}), \beta$-actin, heat shock protein 47 (HSP47), or Smad $1 / 2 / 4$ for $1 \mathrm{~h}$, washed five times with $0.1 \%$ Tween-20 in TBS, and then incubated with an appropriate HRP-conjugated secondary antibody. Detection was performed by using a Pierce Enhanced Chemiluminescence Western Blotting Substrate Kit (Bio-Rad Laboratories, Hercules, California, USA). The detailed information of the antibodies used in this study is provided as follows: Anti-OPN Rabbit Polyclonal antibody (Sigma-Aldrich, St. Louis, Missouri, USA), Anti-OCN Rabbit Polyclonal antibody (Sigma-Aldrich, St. Louis, Missouri, USA), Anti-Collagen I Rabbit Polyclonal antibody (Abcam, Cambridge, UK), Anti-Runx2 Rabbit Polyclonal antibody (Abcam, Cambridge, UK), Anti-HSP47 Rabbit Monoclonal antibody (Clone: EPR4217; Abcam, Cambridge, UK), Anti- $\beta$-Actin Mouse Monoclonal antibody (Clone: mABcam8226; Abcam, Cambridge, UK), Anti-Smad1 Rabbit Monoclonal Antibody (Clone: EP565Y; Abcam, Cambridge, UK), Anti-Smad2 Rabbit Monoclonal Antibody (Clone: EP567Y; Abcam, Cambridge, UK), Anti-Smad1 Rabbit Monoclonal Antibody (Clone: EP618Y; Abcam, Cambridge, UK).

\section{Cell number determination using Cell Counting Kit-8 (CCK-8)}

CCK-8 assay was performed based on a previously described protocol [26, 27]. Briefly, infected C3H10T1/2 cells were grown as described above for $5 \mathrm{~d}$, harvested by trypsinization, and then serially diluted in serum-free BME. Then, $100 \mu \mathrm{L}$ of each dilution was transferred to a clean 96-well microtiter plate, followed the addition of $10 \mu \mathrm{L}$ of CCK-8 Solution (Dojindo Molecular Technologies, Kumamoto, Japan) to each well. The plate was incubated at $37^{\circ} \mathrm{C}$ under a humidified atmosphere containing $5 \% \mathrm{CO}_{2}$ for $2 \mathrm{~h}$ and scanned at $450 \mathrm{~nm}$ on a $\mathrm{UV}-\mathrm{Vis}$ microplate spectrophotometer.

\section{Hoechst staining}

Infected C3H10T1/2 cells were cultivated as described above, harvested, washed with phosphatebuffered saline (PBS), and fixed with a mixed solvent of $75 \%(\mathrm{v} / \mathrm{v})$ methanol and $25 \%(\mathrm{v} / \mathrm{v})$ acetic acid for $30 \mathrm{~min}$. The fixed cells were washed with PBS for 5 min and stained with Hoechst 33258 Solution (Solarbio, Beijing, China) at room temperature for 15 min. After staining, the cells were washed with PBS three times for $5 \mathrm{~min}$ each, and observed under a fluorescence microscope in a mounting medium of $10 \%$ (v/v) glycerol in PBS. The percentage of dividing 
cells per 100 cells was measured and shown in histograms.

\section{Cell cycle analysis}

Adenovirus-infected C3H10T1/2 cells were cultivated as described above, harvested, washed with PBS, and fixed with $70 \%$ ice-cold ethanol at $4{ }^{\circ} \mathrm{C}$ for $48 \mathrm{~h}$. The fixed cells were washed with $100 \mu \mathrm{g} / \mathrm{mL}$ Ribonuclease $\mathrm{H}$ in PBS, incubated at $37^{\circ} \mathrm{C}$ for $30 \mathrm{~min}$, stained with $20 \mu \mathrm{g} / \mathrm{mL}$ propidium iodide in PBS in the dark for $30 \mathrm{~min}$, and subsequently analyzed at 488 $\mathrm{nm}$ on a flow cytometer (BD LSR, Franklin Lakes, New Jersey, USA). DNA was quantitated by using Modfit 2.0 software (Verity Software House, Topsham, Maine, USA).

\section{In vivo bone formation}

All animal experiment procedures were approved by the Ethics Committee of the Second Affiliated Hospital, Chongqing Medical University (No. 2019-340). Fifteen athymic nude (nu/nu) mice (Harlan Laboratories, Indianapolis, Indiana, USA) aged four to six weeks were randomly divided into three equal-sized experiment groups, including the TGF $\beta 1 / B M P 9$ group, the TGF $\beta 1$ group and the BMP9 group. All mice were housed under normal conditions, and were offered food and water ad libitum. C3H10T1/2 cells were infected and then cultivated as described above for $20 \mathrm{~h}$. The infected cells were then collected and resuspended in PBS. The mice were anesthetized with isoflurane and the corneal blink reflex was checked to ensure that all animals were under complete anesthesia. Then, the resuspended cells in PBS were injected into the gastrocnemius muscle on the murine tibia at a dose of $5 \times 10^{6}$ per animal. Specifically, the TGF $\beta 1 /$ BMP9 group were injected with TGF $\beta 1 / \mathrm{BMP} 9$-transduced C3H10T1/2 cells, the TGF $\beta 1$ group with cells that were infected with AdTGF $\beta 1$-RFP and AdGFP, and the BMP9 group with cells that were transduced with AdBMP9-GFP and AdRFP. After five weeks, the mice were euthanized by cervical dislocation and the legs were amputated for microCT imaging. The tissue masses were then resected from the legs and analyzed by hemotoxylin and eosin (H\&E) staining.

\section{Protein microarray analysis}

Protein microarray analysis was conducted by Wanyen Biotechnologies (Shanghai, China), using a custom-made Phospho Explorer Antibody Array (Full Moon BioSystems, Sunnyvale, CA, USA). The microarray consisted of 304 antibodies against 144 non-phosphorylated and 157 phosphorylated proteins with six technical replicates each. For sample preparation, adenovirus-infected C3H10T1/2 cells were cultivated as described above and harvested on
Day 4. C3H10T1/2 cells were lysed in the Extraction Buffer and loaded onto a separation column pre-equilibrated with Labeling Buffer for $60 \mathrm{~min}$, followed by centrifugation at $750 \mathrm{~g}$ for $2 \mathrm{~min}$ to collect the protein flow-through. After BCA quantification, $50 \mu \mathrm{g}$ of the whole cell protein were diluted in Labeling Buffer to a final concentration of $75 \mu \mathrm{L}$ and incubated with $3 \mu \mathrm{L}$ of $10 \mu \mathrm{g} / \mathrm{mL}$ Biotin Reagent in DMF for $2 \mathrm{~h}$ at room temperature with vigorous vortexing. Then, $35 \mu \mathrm{L}$ of Stop Reagent were added and the resultant mixture was vortexed for $30 \mathrm{~min}$. Microarray analysis was performed according the manufacturer's instructions. The array slides were visualized on a SureScan Dx Microarray Scanner (Agilent Technologies, Santa Clara, CA, USA). Data were analyzed and normalized by GenePix Pro (version 6.0; Molecular Devices, San Jose, CA, USA). Outliers were removed by employing the Grubb's test. Based on the normalized data, the levels of each protein in the TGF $\beta 1 / \mathrm{BMP} 9$ group and the BMP9 group were calculated.

\section{Kyoto Encyclopedia of Genes and Genomes (KEGG) pathway analysis}

KEGG pathway analysis was conducted via the KEGG Automatic Annotation Server (https:// www.genome.jp/kegg/kaas). A network of KEGG pathways that were altered between the TGF $\beta 1 /$ BMP9 group and the BMP9 group was constructed with the Pathview Web server (https://pathview. uncc.edu/) based on the microarray data and shown as heat maps.

\section{Statistical analysis}

Statistical analyses were conducted using SPSS 11.0 (IBM, Armonk, New York, USA). Quantitative assays were performed in triplicate and/or repeated in at least three independent experiments. Data were expressed as mean \pm SD. Student's t-test was used to evaluate the statistical significant differences between two experimental groups. $\mathrm{P}<0.05$ was considered statistically significant.

\section{Results}

\section{Increased expression of TGF $\beta 1$ promotes osteogenic differentiation and up-regulates the expression of HSP47 in BMP9-stimulated C3H10T1/2 cells}

We have previously reported that TGF $\beta 1$ exerts an inhibitory effect on BMP9-mediated osteogenic differentiation of MSCs at concentrations above 20 $\mathrm{ng} / \mathrm{mL}$ [22]. Nevertheless, the study employed the supernatant prepared from a culture of TGF $\beta 1$-overexpressing cells, which was ill-suited for in vivo validation. To address this drawback, we opted 
to induce the up-regulation of TGF $\beta 1$ in $\mathrm{C} 3 \mathrm{H} 10 \mathrm{~T} 1 / 2$ cells via adenoviral transduction. We needed to first establish an appropriate transfection protocol to ensure that the cellular level of TGF $\beta 1$ would not exceed $20 \mathrm{ng} / \mathrm{mL}$. To this end, we infected C3H10T1/2 cells with recombinant adenoviruses encoding TGF $\beta 1$ and RFP. We then estimated the transfection efficiency based on the fluorescence intensity of the cells (Figure 1A) and measured the concentration of TGF $\beta 1$ in the culture supernatant via ELISA at day 3 and 7 after the adenoviral infection (Figure 1B). Base on the experimental data, we concluded that the transfection efficiency needed to be at $1 \%$ or less to avoid excessive expression of TGF $\beta 1$.

We then verified the effect of TGF $\beta 1$ on BMP9-dependent osteogenesis of C3H10T1/2 cells. Consistent with the previous study, the cells infected with both AdTGF $\beta 1-R F P$ and AdBMP9-GFP (TGF $\beta 1 /$ BMP9 group) showed a considerably higher level of ALP, as evidenced by the purple stain, than those transduced with AdBMP9-GFP and AdRFP (BMP9 group; Figure 1C). Alizarin red staining demonstrated that the formation of mineralized calcium nodules was much more evident in the TGF $\beta 1 / B M P 9$ group (Figure 1C). Quantitative analysis of osteogenic markers by Western Blotting indicated that TGF $\beta 1$ significantly up-regulated the protein levels of OPN, Runx2, OCN and COL1 in BMP9-transduced cells. Importantly, the TGF $\beta 1 / B M P 9-s t i m u l a t e d$ cells also exhibited significantly augmented expression of HSP47. Taken together, the experimental data confirmed the synergy between TGF $\beta 1$ and BMP9 in promoting the osteogenic differentiation of C 3 H10T1/ 2 cells.

\section{TGF $\beta 1$ suppresses the proliferation of BMP9-induced C3H10T1/2 cells}

It is well known that stem cells maintain a delicate balance between self-renewal and differentiation [28, 29]. Therefore, we hypothesized that TGF $\beta 1$ should exert an inhibitory effect on the proliferation of BMP9-induced C3H10T1/2 cells. This was indeed supported by the measurement of cell count via CCK-8 assay. As illustrated in Figure 2A, cells in the TGF $\beta 1 / \mathrm{BMP} 9$ group proliferated at a similar rate as those in the BMP9 group during the first three days after the adenoviral infection. However, starting from day 3 , the number of proliferative cells in the TGF $\beta 1 / \mathrm{BMP} 9$ group declined rapidly, whereas that of the BMP9 group either showed a moderate drop or remained largely stable. As a result, at day 4 and day 5, there were significantly fewer proliferative cells in the TGF $\beta 1 /$ BMP9 group compared to the BMP9 group, regardless of the transduction efficiency of TGF $\beta 1(1 \%, 5 \%$ or $10 \%)$. The difference in the level of cell proliferation between the two groups was further corroborated by Hoechst staining, which showed fewer TGF $\beta 1 /$ BMP9transduced $\mathrm{C} 3 \mathrm{H} 10 \mathrm{~T} 1 / 2$ cells undergoing mitosis than those induced with only BMP9 on day 1 (Figure 2B). Moreover, cell cycle analysis based on propidium iodide staining revealed that stimulation with TGF $\beta 1$ significantly reduced the percentage of BMP9induced C3H10T1/2 cells in the G2/S phase (Figure 2C). Combined, these experimental results demonstrated that TGF $\beta 1$ could inhibit the proliferation of $\mathrm{BMP9}$-overexpressing $\mathrm{C} 3 \mathrm{H} 10 \mathrm{~T} 1 / 2$ cells.
A

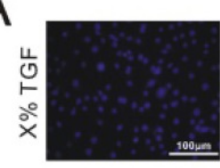

Nuclear stain

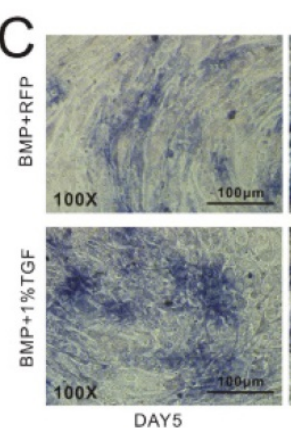

DAY5

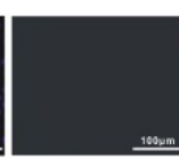

Ctrl

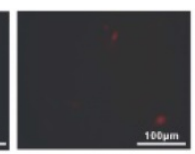

$1 \%$

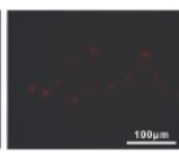

$5 \%$

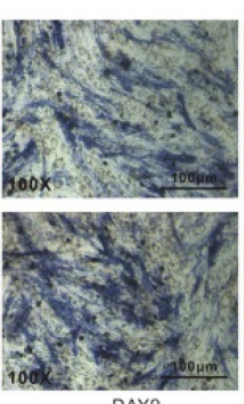

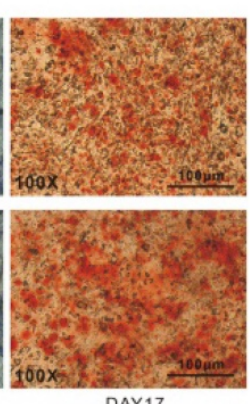

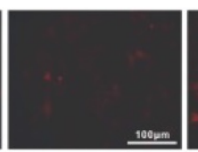

$10 \%$

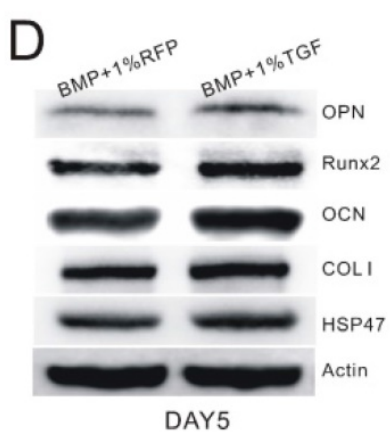

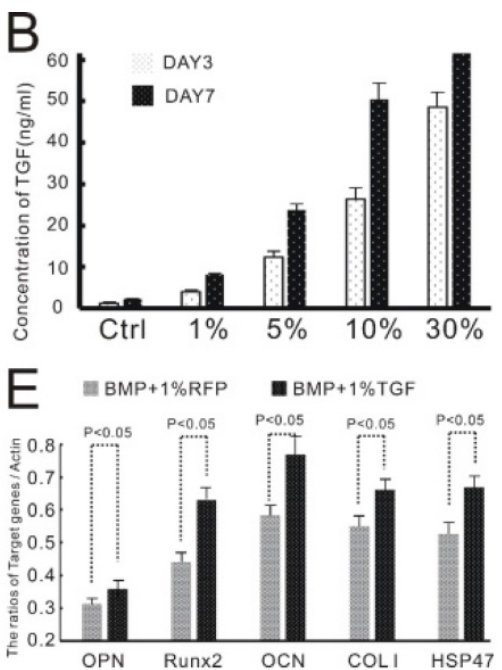

Figure 1. TGF $\beta 1$ promotes osteogenic differentiation and HSP47 expression in BMP9-induced C3H10T1/2 cells. A) Infection of C3H10T1/2 cells with AdTGF 31 -RFP at various levels of transduction efficiency. B) Correlation between the concentration level of TGF $\beta 1$ and the efficiency of adenoviral infection. C) TGF $\beta 1 / B M P 9-s t i m u l a t e d ~ C 3 H 10 T 1 / 2$ cells exhibits increased expression of ALP (day 5 and 9, left and middle) and formation of mineralized calcium nodules (day 17, right) compared to those transduced with BMP9 and RFP. D) Western blot images showing increased protein levels of OPN, Runx2, OCN, COL1 and HSP47 in BMP9-induced C3H10T1/2 cells as a result of TGF 1 overexpression. $\beta$-Actin is used as a control. E) Densitometric quantitation of the Western blot results. 

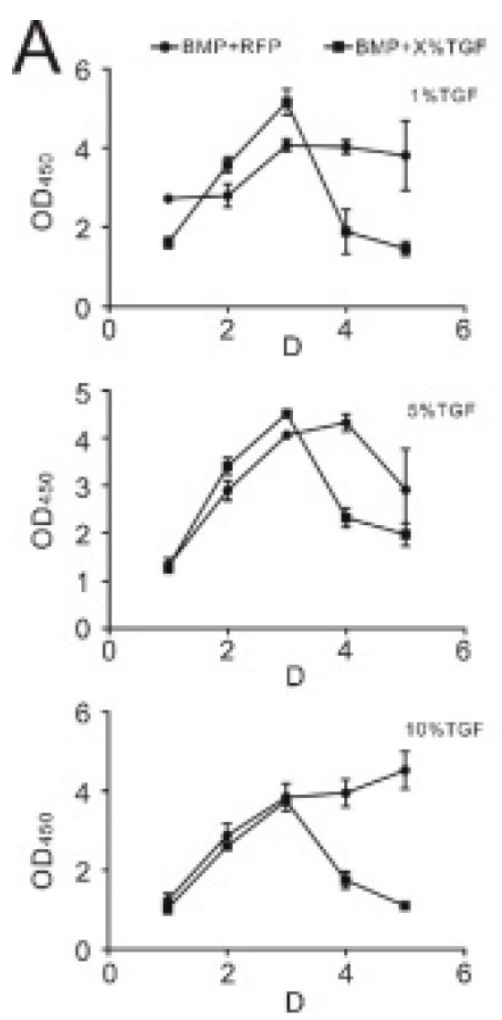
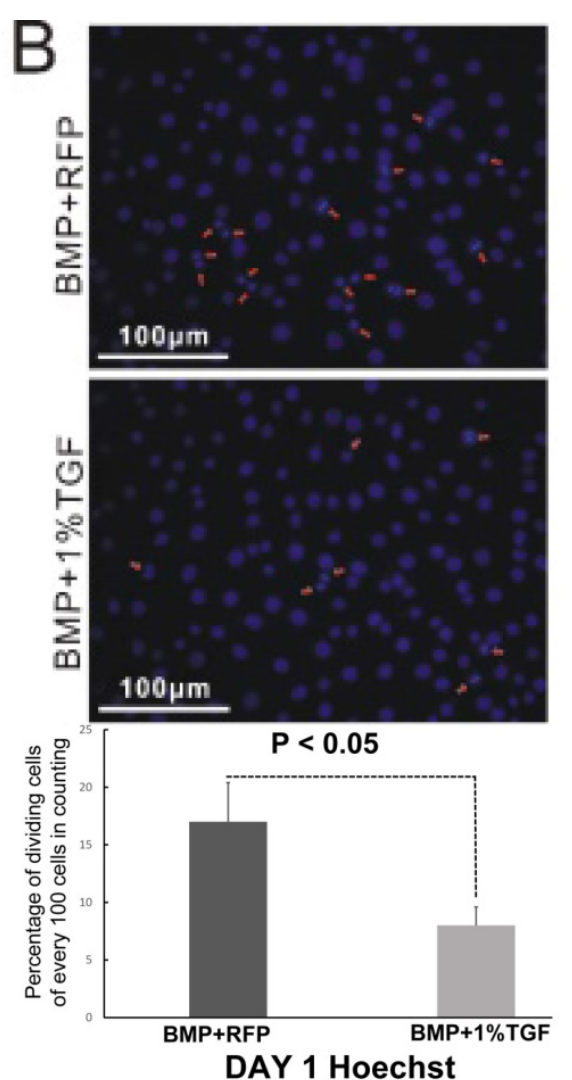

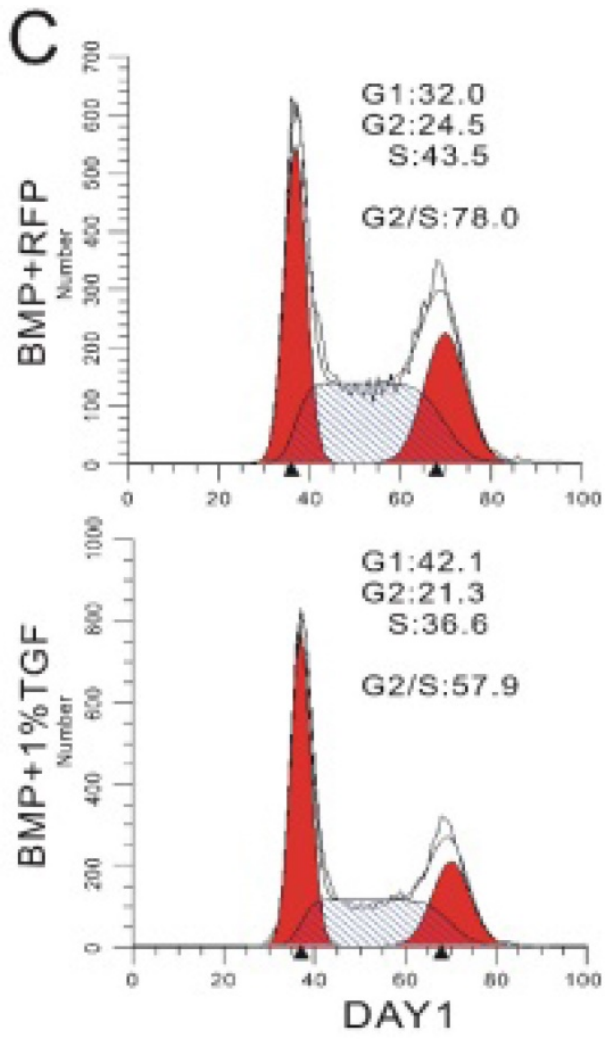

Figure 2. TGF $\beta 1$ inhibits the proliferation of BMP9-induced C3H10T1/2 cells. A) Monitoring of the growth curve of BMP9/RFP- (circle) or TGF $\beta 1 / B M P 9-(s q u a r e)$ transduced C3H10T1/2 cells by CCK-8 analysis. B) Hoechst staining (showing the percentage of dividing cells) and C) flow cytometry-based cell cycle analysis of BMP9/RFP- (top) or TGF $\beta 1 / B M P 9-$ (bottom) transduced C3H10T1/2 cells.

\section{TGF $\beta 1$ enhances BMP9-dependent bone formation from $\mathrm{C} 3 \mathrm{H} 10 \mathrm{~T} 1 / 2$ cells in mice}

Although TGF $\beta 1$ has been shown to promote the osteogenic differentiation of BMP9-induced C3H10T1/2 cells, the lack of animal studies makes it difficult to determine whether such effects could lead to enhanced bone formation in vivo. We thus investigated whether TGF $\beta 1$-dependent osteoinduction that we observed on a cellular level could be replicated in a mouse model. To this end, we intramuscularly injected different types of adenovirally transduced $\mathrm{C} 3 \mathrm{H} 10 \mathrm{~T} 1 / 2$ cells into the gastrocnemius muscle on the murine tibiae and examined the resultant development of ectopic masses on the legs. MicroCT imaging indicated that the average size of the ectopic masses for the BMP9 group was significantly greater than that for the TGF $\beta 1$ / BMP9 group or the TGF $\beta 1$ group (Figure 3A, $B)$. This was in agreement with the anti-proliferative effect of TGF $\beta 1$ described earlier. The ectopic bone matrices were then carefully separated from the masses of legs and examined further. It was found that, unlike the ectopic bone matrices in the other two groups, those resected from the TGF $\beta 1$ group were composed primarily of fibrous rather than bone tissues (Figure 3C), echoing earlier observations that
TGF $\beta 1$ alone could not induce osteogenesis in pluripotent mesenchymal cells [30]. H\&E staining further confirmed that tissue sections prepared from the TGF $\beta 1$ group consisted mainly of fibroblasts and lacked any meaningful bone structures, whereas the bone matrices from the BMP9 group contained intact periosteum and visible trabeculae (Figure 3D). In comparison, the ectopic bone matrices from the TGF $\beta 1 / B M P 9$ group developed more mature osteoid structures, characterized by the presence of thicker trabeculae, periosteum and adipocytes (Figure 3D). Combined, these results provided further evidence that TGF $\beta 1$ could facilitate the formation and maturation of bone tissues from BMP9-induced C3H10T1/ 2 cells.

\section{HSP47 could mediate the osteogenic effect of TGF $\beta 1$ on BMP9-stimulated C3H10T1/2 cells}

As described earlier, we have discovered that the up-regulation of TGF $\beta 1$ in BMP9-induced C3H10T1/2 cells led to increased expression of COL1 and its upstream modulator HSP47. HSP47 has been previously reported to play a key role in the folding and molecular maturation of COL1. Thus, we speculated that HSP47 might mediate TGF 31 -dependent osteogenic differentiation of BMP9-induced C3H10T1/2 cells. Indeed, treatment of TGF $\beta 1 /$ BMP9- 

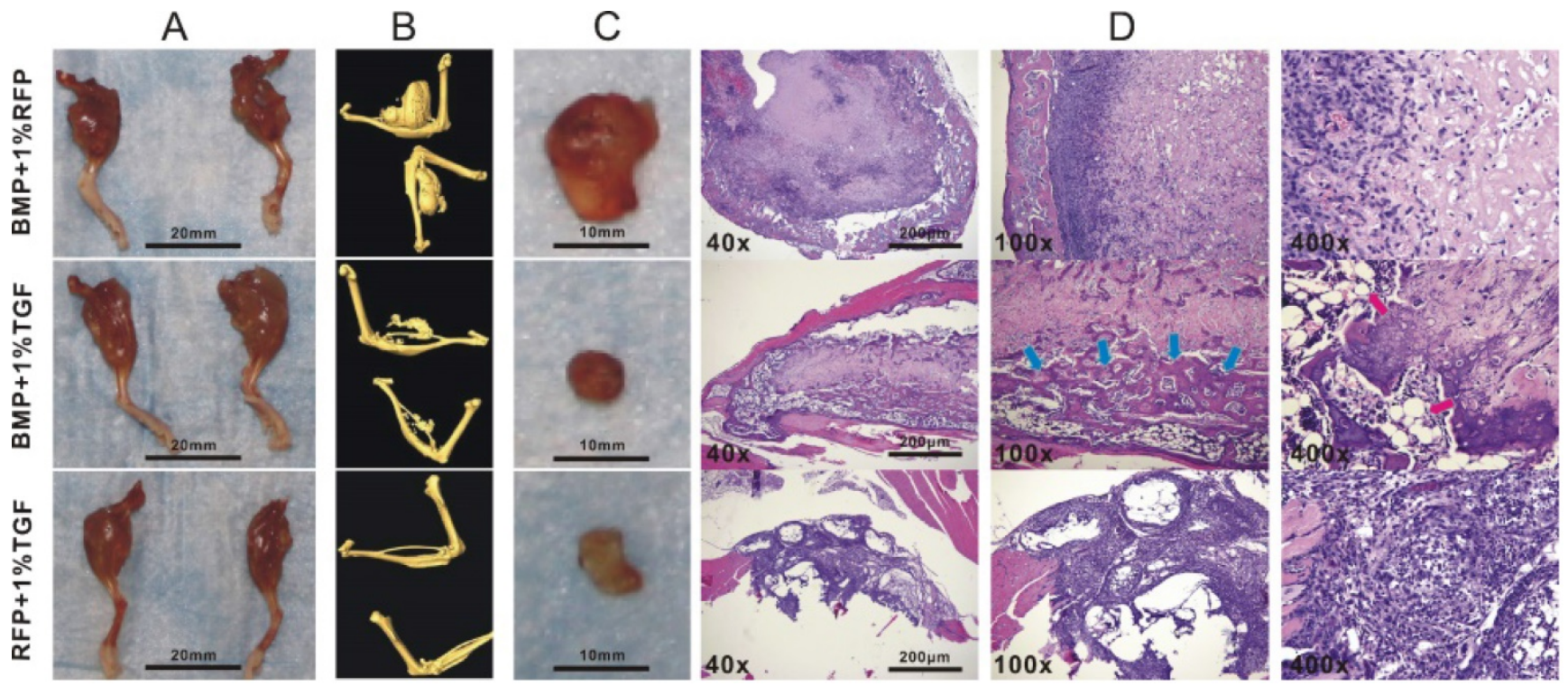

Figure 3. TGF $\beta 1$ enhances bone formation from BMP9-stimulated C3H10T1/2 cells in mice. Athymic nude (nu/nu) mice aged four to six weeks were injected intramuscularly into the gastrocnemius muscle on their tibiae with BMP9/RFP-, TGF $\beta 1 / G F P$-, or TGF $31 / B M P 9-t r a n s d u c e d ~ C 3 H 10 T 1 / 2$ cells. A) Amputated murine legs bearing ectopic bone matrices and B) microCT imaging results. C) Resected ectopic bone matrices. D) H\&E staining showing the presence of periosteum, adipocytes (red arrows) and thicker trabecular structures (blue arrows) in the osteroid sections prepared from the TGF $\beta 1 / B M P 9$ group.
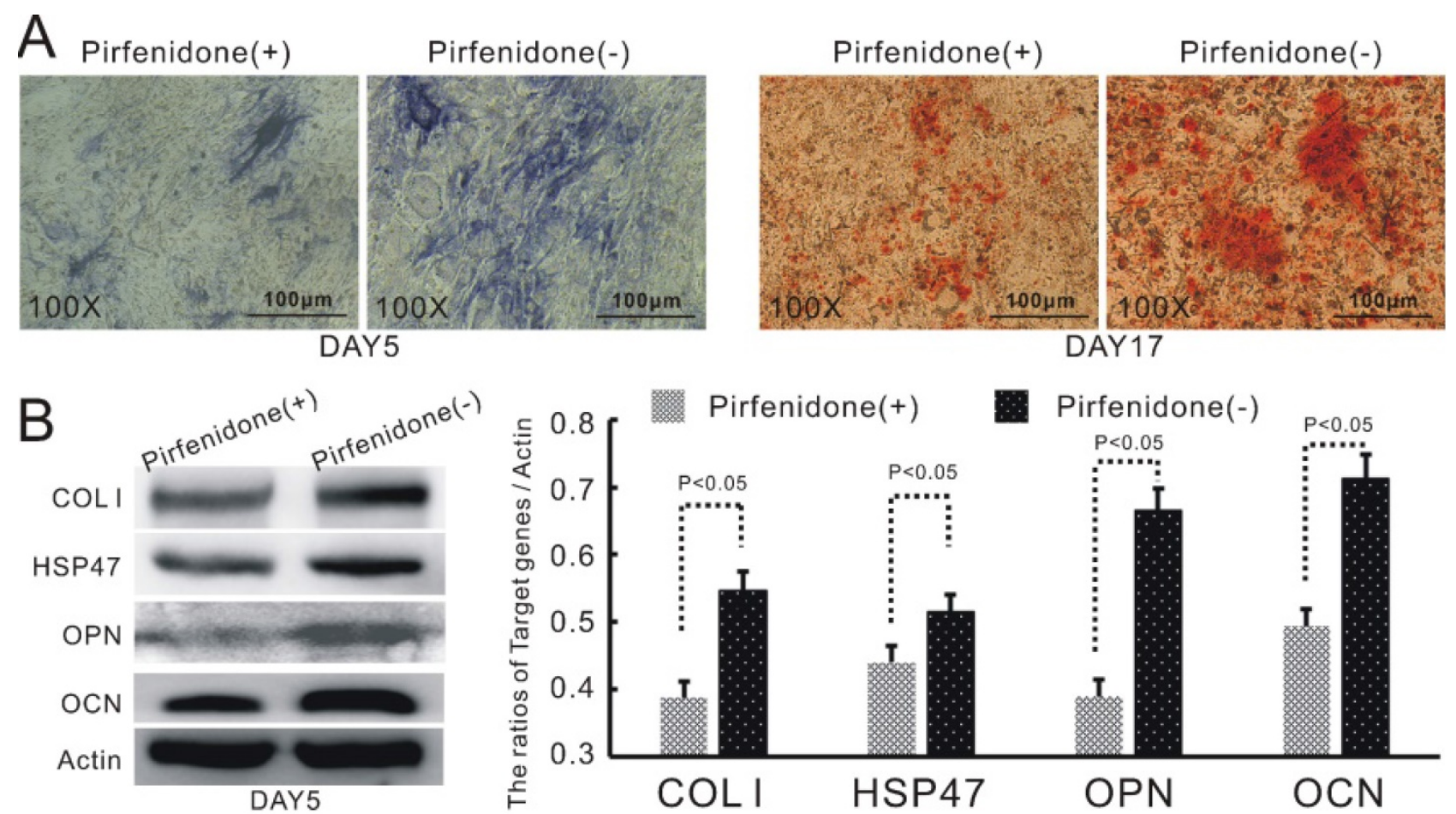

Figure 4. HSP47 mediates TGF $\beta 1$-dependent up-regulation of osteogenic differentiation in BMP9-induced C3H10T1/2 cells. Inhibition of HSP47 by pirfenidone significantly attenuates the stimulatory effects of TGF $\beta 1$ on A) the level of ALP (left) and the formation of mineralized calcium nodules (right), as well as B) the protein expression of COL1, HSP47, OPN and OCN in BMP9-induced C3H10T1/2 cells (left) and densitometric quantitation of the Western blot results (right).

transduced C3H10T1/2 cells with pirfenidone, a wellestablished inhibitor of COL1 and HSP47 [31, 32], was found to markedly attenuate the production of ALP and the formation of mineralized calcium nodules (Figure 4A). Moreover, pirfenidone could also significantly diminish the protein levels of OPN and OCN (Figure 4B). Taken together, these data provided evidence that increased expression of HSP47 could be a contributing factor to the enhanced osteogenic differentiation of TGF $\beta 1 /$ BMP9-stimulated C3H10T1/ 2 cells that we observed in this study.

\section{Treatment of BMP9-induced $\mathrm{C} 3 \mathrm{H} 10 \mathrm{~T} 1 / 2$ cells with TGF $\beta 1$ results in activation of non-canonical signaling pathways}

We next sought to probe the molecular 
mechanisms responsible for the regulatory effect of TGF $\beta 1$ on the osteogenic differentiation of BMP9stimulated C3H10T1/2 cells. Since TGF $\beta /$ Smad was the classical osteogenic signaling pathway, we first examined the expression of Smad1, Smad2 and Smad4, which are the downstream targets of BMP9 [33], TGF $\beta 1$ [19] and TGF $\beta 1 / B M P 9$ [34], respectively. The experimental data that we obtained indicated that the TGF $31 /$ BMP9-tranduced C3H10T1/2 cells had a statistically comparable level of Smad1 and significantly greater level of Smad2 compared to those transduced with BMP9 only (Figure 5A). It came as a surprise that the TGF $\beta 1 / \mathrm{BMP} 9$ group showed a significantly reduced level of Smad4 than the BMP9 group. Since the BMP9 and TGF $\beta 1$ signaling pathways share heterodimeric complexes of type I and II dual-specificity kinase receptors [35], it is possible that increased level of TGF $\beta 1$ might suppress BMP9 regulation of Smad4 through competitive inhibition. At the same time, the lower protein level of Smad4 in the TGF $31 /$ BMP9 group implied that TGF $\beta 1$ could have activated the osteogenic differentiation of C3H10T1/2 cells by non-canonical signaling pathways $[36,37]$.

To probe whether non-canonical signaling mechanisms were involved, we performed microarray analysis to compare between the TGF $\beta 1 /$ BMP9 group and the BMP9 group the expression levels of 304 proteins, including 157 phosphorylated proteins, that are implicated in 16 common pathways associated with cell cycle, adhesion, proliferation, differentiation, apoptosis, etc. Among the phosphorylated proteins that we analyzed, 72 were significantly up-regulated in the TGF $\beta 1 / \mathrm{BMP9}$ transduced cells. KEGG pathway analysis further revealed that a significant number of proteins in the JAK-STAT, PI3K-Akt, and MAPK signaling pathways showed enhanced phosphorylation in the TGF $\beta 1 /$ BMP9 group compared to the BMP9 group (Figure 5B). Therefore, these signaling pathways might play important mechanistic roles in TGF $\beta 1 / B M P 9-$ stimulated bone formation from $\mathrm{C} 3 \mathrm{H} 10 \mathrm{~T} 1 / 2$ cells.

\section{Discussion}

Our current study demonstrated that adenovirally induced up-regulation of TGF $\beta 1$ simultaneously promoted the osteogenic differentiation and attenuated the proliferation of BMP9-induced C3H10T1/2 BMSCs. Importantly, the use of adenoviral vectors allowed us to generate cells that stably overexpressed TGF $\beta 1$ for in vivo investigations. Transplantation of the TGF $\beta 1 /$ BMP9activated $\mathrm{C} 3 \mathrm{H} 10 \mathrm{~T} 1 / 2$ cells into the gastrocnemius muscle of murine tibia led to significant ectopic bone matrices with relatively mature osteoid structures. In comparison, those derived from the BMP9-transduced cells contained less periosteum and trabeculae. These results provided further insight into the synergy between TGF $\beta 1$ and BMP9 in promoting MSC osteogenesis.

Surprisingly, the TGF $\beta 1-B M P 9$ synergy does not seem to act through increased expression of Smad4. $\mathrm{Wu}$ et al. have reported that BMPR2 and ActR2, two type II TGF $\beta 1$ receptors, might be implicated in mediating BMP9-dependent osteogenesis of C3H10T1/2 cells [38]. Previous investigations have revealed that BMP2 could facilitate the heterodimerization of BMPR2 and BMPR1A by binding to both subunits, which in turn could elevate the expression of Smad4 [36]. Because BMP9 has also been shown to interact with BMPR2 in modulating the formation of pulmonary vasculature [39-41], it is possible that a similar regulatory mechanism might be involved in the activation of Smad4. In fact, these findings are consistent with our observation that C3H10T1/2 cells infected with BMP9 exhibited greater expression of Smad4 compared to those transduced with both TGF $\beta 1$ and BMP9. Since TGF $\beta 1$ is known to interact with BMPR2, the apparent attenuation of Smad4 expression by TGF $\beta 1$ in BMP9-induced BMSCs could be the result of competitive inhibition.

Because our initial data failed to produce definitive evidence that TGF $\beta 1$-dependent osteogenesis of BMP9-induced C3H10T1/2 cells was mediated by Smads, we conducted a protein microarray study to probe whether other signaling pathways were involved. Our results suggested that the JAK-STAT, PI3K-Akt and p38 MAPK signaling pathways were activated in the TGF $\beta 1 / B M P 9$ group compared to the BMP9 group. JAK-STAT is primarily known to modulate cytokine signaling [42] but has recently been shown to play a potential role in bone metabolism [43]. There is evidence that the JAK2STAT5B signaling axis could potentially be implicated in osteoblastic differentiation via its modulation of downstream effectors such as Runx2 [44, 45]. Dieudonne et al. demonstrated that interaction of casitas B-linage lymphoma with STAT5 and the subsequent association with Runx2 could augment MSC osteogenesis [46]. On the other hand, experimental findings by Genetos and coworkers indicated that proliferation and osteogenic differentiation of pre-osteoblasts were markedly upregulated by annexin A2 or A5-dependent activation of STAT6 [47]. These findings are consistent with our observation of significantly increased expression levels of STAT6 and STAT5B as a result of TGF $\beta 1$ activation. 

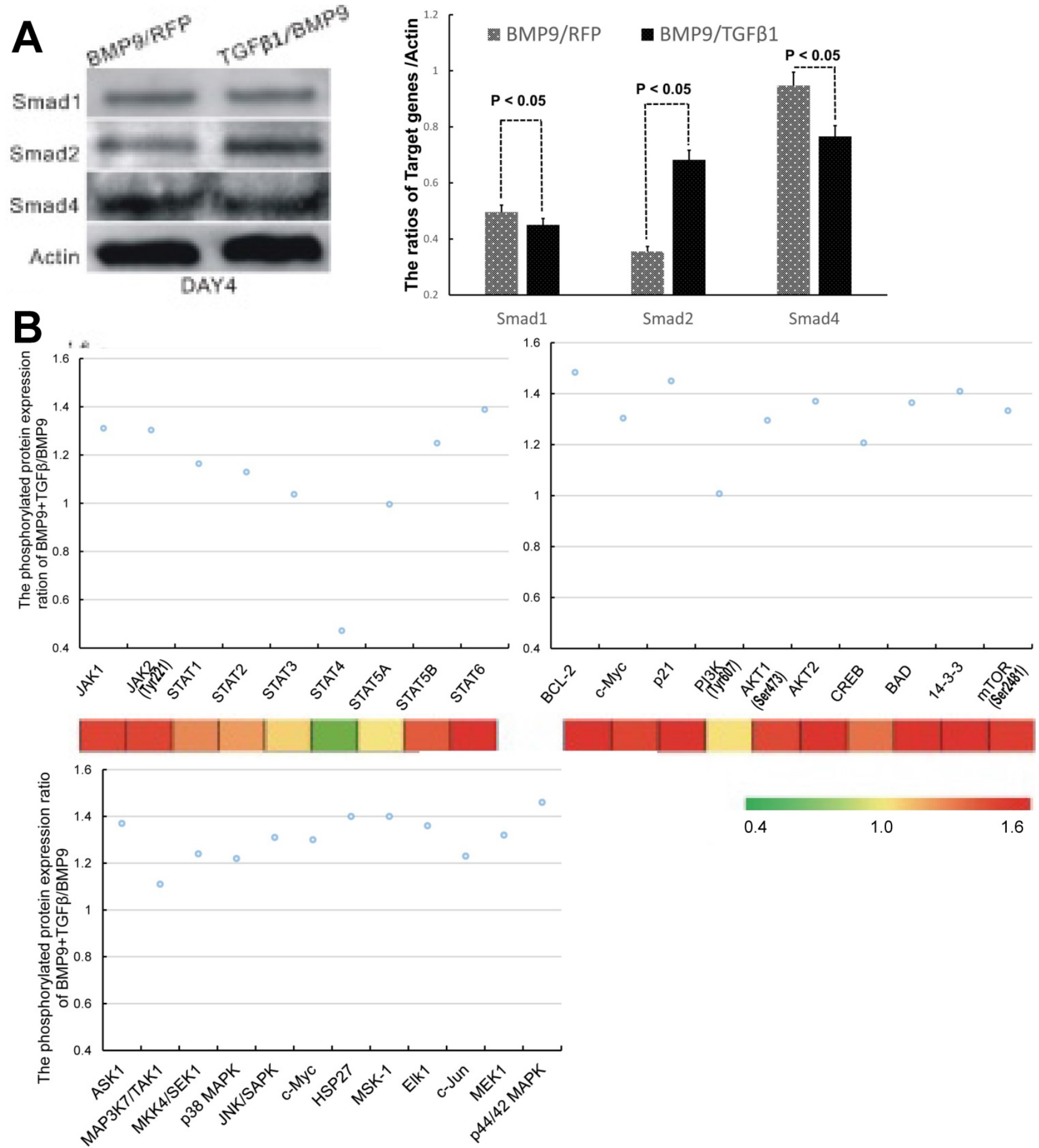

Figure 5. TGF $\beta 1$ might exert its osteogenic effects in BMP9-induced C3H10T1/2 cells via non-canonical signaling pathways. A) Comparison of the protein levels of Smadl, Smad2 and Smad4 between BMP9/RFP- (left, gray) and TGFß1/BMP9- (right, black) transduced C3H10T1/2 cells. B) The phosphorylation levels of selected proteins involved in the JAK-STAT, PI3K-AKT and MAPK signaling pathways.

It is well established that the activation of the PI3K-Akt axis by TGF $\beta 1$ can trigger a wide range of metabolic and cellular effects in different cell types [48-51]. Consistent with our finding, the PI3K-Akt cascade has long been considered as one of the most significant Smad-independent regulatory route for
MSC osteogenesis [52]. For example, Zhang et al. has reported that treatment with $1 \mathrm{ng} / \mathrm{mL}$ of TGF $\beta 1$ augmented the proliferation and mineralization of human hFOB1.19 osteoblasts via the activation of PI3K-Akt [53]. On the other hand, there is also evidence of BMP9-induced enhancement of the 
PI3K-Akt signaling pathway in an osteo-stimulatory context. In Furue et al.'s study, inhibition of PI3K was found to be able to significantly attenuate BMP9dependent up-regulation of ALP and other key osteogenic markers [54]. Furthermore, Eiraku and colleagues showed that BMP9 could accentuate the phosphorylation of Akt and glycogen synthase kinase $3-\beta$ independently of Wnt, resulting in increased expression of ALP and Runx2. It is also interesting to note that PI3K-Akt might also mediate the activation of $\beta$-catenin by TGF $\beta 1$ in human MSCs [55]. Inhibition of $\beta$-catenin has been demonstrated to attenuate BMP9-induced up-regulation of osteogenic markers in MSCs [56], whereas another study indicated that knockdown of $\beta$-catenin could mitigate the inhibitory effect of TGF $\beta 1$ on the production of bone sialoprotein [57]. As a result, $\beta$-catenin seems to demonstrate a complex mechanistic relationship with TGF $\beta 1$ that echoes the latter's own biphasic regulation of BMP9stimulated MSCs. Combined, these findings implied that the interplay between TGF $\beta 1 / B M P 9$ and PI3KAkt could be at least partially responsible for stimulating the osteogenic differentiation of MSCs.

HSP47 is a collagen-specific glycoprotein that belongs to the serpin family, and has been found to play a critical role in collagen maturation [58, 59]. Importantly, HSP47 has been regularly shown to be targeted by TGF $\beta 1$ in fibrosis. For example, TGF $\beta 1$ has been reported to elevate both the mRNA and protein levels of HSP47 and COL1 in human lung fibroblasts, and such effects can be attenuated by pirfenidone [31]. TGF $\beta 1$-induced stimulation of HSP47 was also observed in the stromal fibroblasts obtained from the conjunctival tissues of patients with ocular cicatricial pemphigoid [60]. A survey of past studies implied that the activation of HSP47 by TGF $\beta 1$ might involve a set of complex and even opposing mechanisms. Xiao and colleagues revealed that suppression of JNK could block TGF $\beta 1$-induced activation of HSP47 and the resultant increase of extracellular matrix (ECM) synthesis in a human proximal tubular epithelial cell line HK-2 [61]. In another study, Stambe and coworkers revealed that the stimulatory effect of TGF $\beta 1$ on collagen synthesis could be attenuated by the inhibition of p38, which concomitantly diminished the protein level of HSP47 [62]. These results coincided with the increased phosphorylation levels of p38 and JNK that we observed in the TGF $\beta 1 / \mathrm{BMP} 9$ group compared to the BMP9 group. On the other hand, it should also be pointed out that the canonical Smad signaling pathway might also play an important role, as evidenced by Kim et al.'s finding that Smad2/3 was mechanistically implicated in TGF $\beta 1$-dependent up-regulation of HSP47 and ECM production in nasal fibroblasts [63]. As elucidated earlier, enhanced production of COL1 could lead to the development of a well-connected collagen fiber network, which is beneficial for bone formation, by facilitating calcium deposition and osteoid maturation. Therefore, we speculated that HSP47-mediated augmentation of collagen synthesis by TGF $\beta 1$ could synergize with BMP9-dependent bone apposition and mineralization.

In conclusion, our study demonstrated that TGF $\beta 1$ could promote the osteogenic differentiation and inhibit the proliferation of BMP9-induced C13H10T1/2 cells, which, when replicated in mice, resulted in enhanced bone formation characterized by a more mature collagen-matrix structure and a greater extent of calcium mineralization. We showed that HSP47, which modulates COL1 expression, was upregulated by TGF $\beta 1$, whereas inhibition of HSP47 by pirfenidone significantly mitigated the osteogenic effects of TGF $\beta 1$. Furthermore, our microarray studies suggested that the observed enhancement of bone formation might act through non-canonical signaling pathways. These results provided useful insights into the molecular mechanisms responsible for TGF $\beta 1$ dependent osteo-induction of BMSCs.

\section{Acknowledgements}

\section{Funding}

This work was supported by research grants from the Natural Science Foundation of China (Grant\# 81601895 to RL).

\section{Competing Interests}

The authors have declared that no competing interest exists.

\section{References}

1. van Deurs B, Hansen SH, Petersen OW, Melby EL, Sandvig K. Endocytosis, intracellular transport and transcytosis of the toxic protein ricin by a polarized epithelium. Eur J Cell Biol. 1990; 51: 96-109.

2. Locker PH, Arthur J, Edmiston T, Puri R, Levine BR. Management of Bone Defects in Orthopedic Trauma. Bull Hosp Jt Dis (2013). 2018; 76: 278-84.

3. Maisel AS, Gilpin EA, Klein L, Le Winter M, Henning H, Collins D. The murmur of papillary muscle dysfunction in acute myocardial infarction: clinical features and prognostic implications. Am Heart J. 1986; 112: 705-11.

4. Prockop DJ. Marrow stromal cells as stem cells for nonhematopoietic tissues. Science. 1997; 276: 71-4.

5. Panetta NJ, Gupta DM, Quarto N, Longaker MT. Mesenchymal cells for skeletal tissue engineering. Panminerva Med. 2009; 51: 25-41.

6. Ben-Ari A, Rivkin R, Frishman M, Gaberman E, Levdansky L, Gorodetsky R. Isolation and implantation of bone marrow-derived mesenchymal stem cells with fibrin micro beads to repair a critical-size bone defect in mice. Tissue Eng Part A. 2009; 15: 2537-46.

7. Long T, Zhu Z, Awad HA, Schwarz EM, Hilton MJ, Dong Y. The effect of mesenchymal stem cell sheets on structural allograft healing of critical sized femoral defects in mice. Biomaterials. 2014; 35: 2752-9.

8. Chen W, Liu J, Manuchehrabadi N, Weir MD, Zhu Z, Xu HH. Umbilical cord and bone marrow mesenchymal stem cell seeding on macroporous calcium phosphate for bone regeneration in rat cranial defects. Biomaterials. 2013; 34: 9917-25. 
9. Zhou $\mathrm{W}, \mathrm{Liu} \mathrm{Q}, \mathrm{Xu}$ B. Improvement of bone defect healing in rats via mesenchymal stem cell supernatant. Exp Ther Med. 2018; 15: 1500-4.

10. Takacs R, Matta C, Somogyi C, Juhasz T, Zakany R. Comparative analysis of osteogenic/chondrogenic differentiation potential in primary limb bud-derived and C3H10T1/2 cell line-based mouse micromass cultures. Int J Mol Sci. 2013; 14: 16141-67.

11. Zhao L, Li G, Chan KM, Wang Y, Tang PF. Comparison of multipotent differentiation potentials of murine primary bone marrow stromal cells and mesenchymal stem cell line C3H10T1/2. Calcif Tissue Int. 2009; 84: 56-64.

12. Gan Y, Dai K, Zhang P, Tang T, Zhu Z, Lu J. The clinical use of enriched bone marrow stem cells combined with porous beta-tricalcium phosphate in posterior spinal fusion. Biomaterials. 2008; 29: 3973-82.

13. Lamplot JD, Qin J, Nan G, Wang J, Liu X, Yin L, et al. BMP9 signaling in stem cell differentiation and osteogenesis. Am J Stem Cells. 2013; 2: 1-21.

14. Luu HH, Song WX, Luo X, Manning D, Luo J, Deng ZL, et al. Distinct roles of bone morphogenetic proteins in osteogenic differentiation of mesenchymal stem cells. J Orthop Res. 2007; 25: 665-77.

15. Deng ZL, Sharff KA, Tang N, Song WX, Luo J, Luo X, et al. Regulation of osteogenic differentiation during skeletal development. Front Biosci. 2008; 13: 2001-21.

16. Ji C, Liu X, Xu L, Yu T, Dong C, Luo J. RUNX1 Plays an Important Role in Mediating BMP9-Induced Osteogenic Differentiation of Mesenchymal Stem Cells Line C3H10T1/2, Murine Multi-Lineage Cells Lines C2C12 and MEFs. Int J Mol Sci. 2017; 18.

17. Kang Q, Song WX, Luo Q, Tang N, Luo J, Luo X, et al. A comprehensive analysis of the dual roles of BMPs in regulating adipogenic and osteogenic differentiation of mesenchymal progenitor cells. Stem Cells Dev. 2009; 18: 545-59.

18. Massague J. TGF-beta signal transduction. Annu Rev Biochem. 1998; 67: 753-91.

19. Gomez-Puerto MC, Iyengar PV, Garcia de Vinuesa A, Ten Dijke P, Sanchez-Duffhues G. Bone morphogenetic protein receptor signal transduction in human disease. J Pathol. 2019; 247: 9-20.

20. Xu DJ, Zhao YZ, Wang J, He JW, Weng YG, Luo JY. Smads, p38 and ERK1/2 are involved in BMP9-induced osteogenic differentiation of C3H10T1/2 mesenchymal stem cells. BMB Rep. 2012; 45: 247-52.

21. Hering S, Isken E, Knabbe C, Janott J, Jost C, Pommer A, et al. TGFbeta1 and TGFbeta2 mRNA and protein expression in human bone samples. Exp Clin Endocrinol Diabetes. 2001; 109: 217-26.

22. Li RD, Deng ZL, Hu N, Liang X, Liu B, Luo J, et al. Biphasic effects of TGFbeta1 on BMP9-induced osteogenic differentiation of mesenchymal stem cells. BMB Rep. 2012; 45: 509-14.

23. Janssens K, ten Dijke P, Janssens S, Van Hul W. Transforming growth factor-beta1 to the bone. Endocr Rev. 2005; 26: 743-74.

24. Hisatomi K, Mukae H, Sakamoto N, Ishimatsu Y, Kakugawa T, Hara S, et al. Pirfenidone inhibits TGF-beta1-induced over-expression of collagen type I and heat shock protein 47 in A549 cells. BMC Pulm Med. 2012; 12: 24.

25. Luo J, Deng ZL, Luo X, Tang N, Song WX, Chen J, et al. A protocol for rapid generation of recombinant adenoviruses using the AdEasy system. Nat Protoc. 2007; 2: 1236-47.

26. Yang G, Zhang T, Ye J, Yang J, Chen C, Cai S, et al. Circ-ITGA7 sponges miR-3187-3p to upregulate ASXL1, suppressing colorectal cancer proliferation. Cancer Manag Res. 2019; 11: 6499-509.

27. Yang $\mathrm{XH}$, Zhuang $\mathrm{MK}$, Xie $\mathrm{WH}, \mathrm{Du} \mathrm{F}$, Huang $\mathrm{YH}$, Chen $\mathrm{ZX}$, et al 12-Lipoxygenase promotes epithelial-mesenchymal transition via the Wnt/beta-catenin signaling pathway in gastric cancer cells. Onco Targets Ther. 2019; 12: 5551-61.

28. Tang N, Song WX, Luo J, Haydon RC, He TC. Osteosarcoma development and stem cell differentiation. Clin Orthop Relat Res. 2008; 466: 2114-30.

29. Merrilees MJ. Epidermal fine structure of the teleost Esox americanus (Esocidae, Salmoniformes). J Ultrastruct Res. 1974; 47: 272-83.

30. Bonewald LF, Mundy GR. Role of transforming growth factor beta in bone remodeling: a review. Connect Tissue Res. 1989; 23: 201-8.

31. Nakayama S, Mukae H, Sakamoto N, Kakugawa T, Yoshioka S, Soda $\mathrm{H}$ et al. Pirfenidone inhibits the expression of HSP47 in TGF-beta1-stimulated human lung fibroblasts. Life Sci. 2008; 82: 210-7.

32. Kakugawa $T$, Mukae H, Hayashi $T$, Ishii $H$, Abe $K$, Fujii $T$, et al. Pirfenidone attenuates expression of HSP47 in murine bleomycin-induced pulmonary fibrosis. Eur Respir J. 2004; 24: 57-65.

33. Chen D, Zhao M, Mundy GR. Bone morphogenetic proteins. Growth Factors. 2004; 22: 233-41.

34. Nishimura R, Hata K, Ikeda F, Matsubara T, Yamashita K, Ichida F, et al. The role of Smads in BMP signaling. Front Biosci. 2003; 8: s275-84.

35. Heldin $\mathrm{CH}$, Moustakas A. Signaling Receptors for TGF-beta Family Members. Cold Spring Harb Perspect Biol. 2016; 8.
36. Rahman MS, Akhtar N, Jamil HM, Banik RS, Asaduzzaman SM. TGF-beta/BMP signaling and other molecular events: regulation of osteoblastogenesis and bone formation. Bone Res. 2015; 3: 15005.

37. Herpin A, Cunningham C. Cross-talk between the bone morphogenetic protein pathway and other major signaling pathways results in tightly regulated cell-specific outcomes. FEBS J. 2007; 274: 2977-85.

38. Wu N, Zhao Y, Yin Y, Zhang Y, Luo J. Identification and analysis of type II TGF-beta receptors in BMP-9-induced osteogenic differentiation of C3H10T1/2 mesenchymal stem cells. Acta Biochim Biophys Sin (Shanghai). 2010; 42: 699-708.

39. Long L, Ormiston ML, Yang X, Southwood M, Graf S, Machado RD, et al. Selective enhancement of endothelial BMPR-II with BMP9 reverses pulmonary arterial hypertension. Nat Med. 2015; 21: 777-85.

40. Tillet E, Bailly S. Emerging roles of BMP9 and BMP10 in hereditary hemorrhagic telangiectasia. Front Genet. 2014; 5: 456

41. Orriols M, Gomez-Puerto MC, Ten Dijke P. BMP type II receptor as a therapeutic target in pulmonary arterial hypertension. Cell Mol Life Sci. 2017; 74: 2979-95.

42. Luo K. Signaling Cross Talk between TGF-beta/Smad and Other Signaling Pathways. Cold Spring Harb Perspect Biol. 2017; 9.

43. Li J. JAK-STAT and bone metabolism. JAKSTAT. 2013; 2: e23930.

44. Darvin P, Joung YH, Yang YM. JAK2-STAT5B pathway and osteoblast differentiation. JAKSTAT. 2013; 2: e24931.

45. Joung YH, Lim EJ, Darvin P, Chung SC, Jang JW, Do Park K, et al. MSM enhances GH signaling via the Jak2/STAT5b pathway in osteoblast-like cells and osteoblast differentiation through the activation of STAT5b in MSCs. PLoS One. 2012; 7: e47477.

46. Dieudonne FX, Severe N, Biosse-Duplan M, Weng JJ, Su Y, Marie PJ. Promotion of osteoblast differentiation in mesenchymal cells through Cbl-mediated control of STAT5 activity. Stem Cells. 2013; 31: 1340-9.

47. Genetos DC, Wong A, Weber TJ, Karin NJ, Yellowley CE. Impaired osteoblast differentiation in annexin A2- and -A5-deficient cells. PLoS One. 2014; 9: e107482.

48. Rodriguez-Garcia A, Samso P, Fontova P, Simon-Molas H, Manzano A, Castano E, et al. TGF-beta1 targets Smad, p38 MAPK, and PI3K/Akt signaling pathways to induce PFKFB3 gene expression and glycolysis in glioblastoma cells. FEBS J. 2017; 284: 3437-54.

49. Hamidi A, Song J, Thakur N, Itoh S, Marcusson A, Bergh A, et al. TGF-beta promotes PI3K-AKT signaling and prostate cancer cell migration through the TRAF6-mediated ubiquitylation of p85alpha. Sci Signal. 2017; 10.

50. Chen QZ, Li Y, Shao Y, Zeng YH, Ren WY, Liu RX, et al. TGF-beta1/PTEN/PI3K signaling plays a critical role in the anti-proliferation effect of tetrandrine in human colon cancer cells. Int J Oncol. 2017; 50: 1011-21.

51. Zhang L, Zhou F, ten Dijke P. Signaling interplay between transforming growth factor-beta receptor and PI3K/AKT pathways in cancer. Trends Biochem Sci. 2013; 38: 612-20.

52. Karner CM, Lee SY, Long F. Bmp Induces Osteoblast Differentiation through both Smad4 and mTORC1 Signaling. Mol Cell Biol. 2017; 37.

53. Zhang Z, Zhang $X$, Zhao D, Liu B, Wang B, Yu W, et al. TGFbeta1 promotes the osteoinduction of human osteoblasts via the PI3K/AKT/mTOR/S6K1 signalling pathway. Mol Med Rep. 2019; 19: 3505-18.

54. Furue K, Sena K, Sakoda K, Nakamura T, Noguchi K. Involvement of the phosphoinositide 3-kinase/Akt signaling pathway in bone morphogenetic protein 9-stimulated osteogenic differentiation and stromal cell-derived factor 1 production in human periodontal ligament fibroblasts. Eur J Oral Sci. 2017; 125: 119-26.

55. Eiraku N, Chiba N, Nakamura T, Amir MS, Seong CH, Ohnishi T, et al. BMP9 directly induces rapid GSK3-beta phosphorylation in a Wnt-independent manner through class I PI3K-Akt axis in osteoblasts. FASEB J. 2019; 33: 12124-34.

56. Tang N, Song WX, Luo J, Luo X, Chen J, Sharff KA, et al. BMP-9-induced osteogenic differentiation of mesenchymal progenitors requires functional canonical Wnt/beta-catenin signalling. J Cell Mol Med. 2009; 13: 2448-64.

57. Buus S, Werdelin O. A group-specific inhibitor of lysosomal cysteine proteinases selectively inhibits both proteolytic degradation and presentation of the antigen dinitrophenyl-poly-L-lysine by guinea pig accessory cells to T cells. J Immunol. 1986; 136: 452-8.

58. Ishida Y, Nagata K. HSP47 as a collagen-specific molecular chaperone. Methods Enzymol. 2011; 499: 167-82.

59. Ito S, Nagata K. Biology of HSP47 (Serpin H1), a collagen-specific molecular chaperone. Semin Cell Dev Biol. 2017; 62: 142-51.

60. Razzaque MS, Foster CS, Ahmed AR. Role of collagen-binding heat shock protein 47 and transforming growth factor-beta1 in conjunctival scarring in ocular cicatricial pemphigoid. Invest Ophthalmol Vis Sci. 2003; 44: 1616-21. 
61. Xiao HB, Liu RH, Ling GH, Xiao L, Xia YC, Liu FY, et al. HSP47 regulates ECM accumulation in renal proximal tubular cells induced by TGF-beta1 through ERK1/2 and JNK MAPK pathways. Am J Physiol Renal Physiol. 2012; 303: F757-65.

62. Stambe C, Atkins RC, Tesch GH, Masaki T, Schreiner GF, Nikolic-Paterson DJ. The role of p38alpha mitogen-activated protein kinase activation in renal fibrosis. J Am Soc Nephrol. 2004; 15: 370-9.

63. Kim HJ, Park JH, Shin JM, Yang HW, Lee HM, Park IH. TGF-beta1-induced HSP47 regulates extracellular matrix accumulation via Smad2/3 signaling pathways in nasal fibroblasts. Sci Rep. 2019; 9: 15563. 